\title{
From Rote to Wrote: College Admission via Secure ePortfolios
}

\author{
Richard C. Larson'1, Soheil Sibdari² \\ ${ }^{1}$ Institute for Data, Systems, and Society, Massachusetts Institute of Technology, Cambridge, Massachusetts, USA \\ ${ }^{2}$ Decision \& Information Sciences, University of Massachusetts, Dartmouth, Massachusetts, USA \\ Email: rclarson@mit.edu
}

How to cite this paper: Larson, R. C., \& Sibdari, S. (2020). From Rote to Wrote: College Admission via Secure ePortfolios. Creative Education, 11, 1580-1601. https://doi.org/10.4236/ce.2020.119116

Received: July 17, 2020

Accepted: September 5, 2020

Published: September 8, 2020

Copyright $\odot 2020$ by author(s) and Scientific Research Publishing Inc. This work is licensed under the Creative Commons Attribution International License (CC BY 4.0).

http://creativecommons.org/licenses/by/4.0/

\begin{abstract}
Our focus is high school students following STEM learning paths, where STEM = Science, Technology, Engineering, and Mathematics. We argue for a new system replacing test-focused rote learning with deep reflective learning. Fortunately, new movements in education are supportive of this objective. Growing numbers of colleges and universities are reducing or even removing the evaluative weights placed on standardized tests such as the SAT and ACT. We suggest replacing these tests with secure and vetted student electronic portfolios (ePortfolios) that feature many artifacts of a student's high school achievements, especially those associated with Project-Based Learning (PBL), as well as the student's personal written reflections recorded over four years of learning. This more personalized admissions process will provide evaluative information far richer than what is currently available. The proposed ePortfolio process should reduce biases associated with standardized tests, biases related to gender, race, community wealth, and family wealth. Successful scaled implementation of ePortfolios will require several significant, and integrated changes in our educational system: college admissions offices reducing the importance weights of standardized tests; high schools filling the gap with ePortfolio content, requiring high school students to create ePortfolios from freshman year onward; restructuring processes to provide numerous project-based learning activities for students throughout high school; and providing approaches and tools for high school teachers and college admissions offices to assess ePortfolio content.
\end{abstract}

\section{Keywords}

High School, STEM, Student Portfolios, Project-Based Learning, Standardized Tests, SAT, ACT 


\section{Introduction}

The transition from high school to college or university is among the most important in a person's life. His or her entire future will depend in many ways on how this transition occurs and on its outcome. Our paper focuses on what we believe will substantially improve this transition: educational structural changes featuring student ePortfolios, including new active learning opportunities for creating ePortfolio content and new comprehensive ways to assess student accomplishments.

A summary portfolio of one's accomplishments-known as a resume or curriculum vitae $(\mathrm{CV})$ - is well recognized in adult life. Adults use resumes in applying for jobs; their contents provide succinct information on previous job-relevant professional activities. Those evaluating the candidate can use the resume as an interview guide, often requesting more detail about various resume entries. In the job application process, the candidate warrants the truthfulness of the entire resume. Fabrications discovered after hiring are grounds for dismissal.

Young people, typically 18-year-olds, who are applying to college, are evaluated quite differently.

In order to argue for ePortfolios, we need to provide context, the typical procedures in applying to a college or university. In the remainder of this Section 1, we describe the current college admission process, and we discuss the challenges, including biases of using standardized tests in the admission process. We include a discussion on how the 2020 COVID-19 pandemic demonstrates the need for alternative assessment tools for college admission such as ePortfolios. A roadmap of the remainder of the paper appears at the end of this Section 1.

\subsection{Applying to College}

College applicants are typically asked to submit a set of items: scores on standardized multiple-choice tests (e.g., SAT and ACT); grades earned in high school courses; letters of recommendation; personal statements; and information on extracurricular activities. College admissions officers typically use scores and grades as first-level screening criteria, with those who fail to "make the grade" removed from further consideration. Further evaluation of candidates surviving the first cut relies on all the other submitted information. Competition is intense, with acceptance percentages at premier universities often in single digits.

\subsection{Testmania: SAT and ACT}

Preparing for and applying to college is expensive. Families spend an average of $\$ 1700$ for standardized tests and application fees; most students apply to at least three colleges, and 35 percent apply to at least seven (Mulhere, 2017).

Many educators believe that reliance on standardized tests is a defective process. First, these tests measure only a few skills that reward memorization and fast test-taking strategies, while true interests and passions remain hidden. However, for colleges, these tests do provide a low-cost, semi-automated way to 
review and admit students. The scores are also known to be good predictors for some types of academic performance. Mattern \& Patterson measured the predictability power of SAT scores and showed that the first-year grade point average (FYGPA) is well linked to the student's SAT SCORE (Mattern \& Patterson, 2009). Using 2006 data from 106 four-year institutions, they showed that the scores can also predict the second-year retention rate. Among SAT high performers, 95.5 percent return to the college in the second year compared to only 63.8 percent of the low performers. Given these known advantages-low cost and grade point predictability-most colleges still rely on standardized tests.

From our point of view, though, the huge evaluative weight college admissions systems place on standardized test scores carries unacceptable negatives, many with social justice attributes. First, the test-taking skill of the candidate is the top measure for surviving the first cut. A high score rewards a student's memorization capability as well as her/his ability to perform in an artificial time-constrained, anxiety-provoking, test-taking environment, one unlikely ever to be replicated in professional life. The test score criterion is often defended as "fair" to all applicants, allegedly supporting a strict meritocracy model of the admissions process. But experience shows the tests to be unfair when viewed across socio-economic dimensions. Families with financial means have numerous built-in advantages. They tend to live in more wealthy communities with large property tax bases, implying good or excellent schools. Specific to the tests, they can hire tutors to advance their children's test-taking skills, afford to have their children take the expensive test multiple times and submit only the best scores, purchase test-taking practice books written by those who create the tests, and even seek extra time for their children to take the tests (via "specialists") (Hess, 2019).

The children of poorer families, who have none of these advantages, enter the testing process at a severe disadvantage. The disadvantages disproportionately affect minorities, rural families, and other lower-income groups (Hess, 2019; Broussard, 2014; Reeves \& Halikias, 2017; Harker, 2014, Larson \& Murray, 2019). According to (Belkin, 2019), the College Board says it discovered SAT scores correlated closely with family income. Admissions officers and guidance counselors came to see the test as a "gatekeeper of privilege rather than a leveler on merit." For over a year, the University of California system has considered abandoning the SAT/ACT requirement in admissions (Strachan, 2019; Watanabe, 2019), and recently announced that policy as a final decision: SAT and ACT no longer required (Sandler, 2020). (DeGeurin, 2019) provides a list of universities and colleges that do not require SAT or ACT scores including many other top-tier schools. With the ongoing COVID-19 pandemic, many other universities including Cornell, Columbia, and Dartmouth College have waived the SAT requirement toward admission. This decision was based on the significant challenges that students would face to schedule the test, and take the test in a fair and safe environment due to the pandemic (Anderson, 2020). Temporary sus- 
pension of the tests during the pandemic might become a longer-term practice, and many universities might adopt the test-optional or no-test policy.

These standardized tests have also been found to be gender biased: females equally accomplished in high school with male counterparts tend to score lower on the tests, due in part to their reluctance to play the probability game of guessing the right answer once they have narrowed the choices down to two. This situation occurs often in multiple choice tests, as the test taker says to herself, "I know for sure that option (b) or option (d) is correct, but not which one. I'm thinking it's 50-50." Guessing the right answer increases one's score by plus 1.0; guessing incorrectly drops one's score by minus $1 / 4$. Analyses have shown that males-being more risk prone-are more likely to play this game, as they can discern that the expected value of the guessing strategy is positive (it's actually $+3 / 8$ ). Females, even as they may know the probabilities, are more risk averse and reluctant to offer an answer they know has a 50-percent chance of being "wrong", so they-not wanting to be wrong-prefer to leave a blank sheet (Baldiga, 2013). Gender bias is rooted in other causes as well, such as males being more likely to write the questions (FairTest, 2007).

Beyond bias, there is the question of whether high test scores always indicate the types of students desired first by colleges and eventually by employers? On the affirmative side, for students leaning toward STEM subjects (Science, Technology, Engineering, Mathematics), these tests can verify the student's knowledge of fundamentals in math and science. Universities and eventual employers are looking for students with strong fundamental knowledge as a prerequisite, but more than that, they seek those who can tackle previously unseen problems, armed only with a blank sheet of paper and equipped with deep critical and creative thinking skills. In new problem settings, memorized algorithms are irrelevant; "plug and chug" and "drill-and-kill" solutions to such problems do not exist. Students in problem framing and formulation settings also need "soft skills" to work with others, including communication, collaboration, and teamwork skills. Standardized tests score zero in measuring these abilities. China is famous for its high stress, two-day Gaokao test. But educators in China are becoming increasingly frustrated with the Gaokao since high tests scores do not imply creative and critical thinkers but rather rote memorizers, not what the Chinese economy wants (The Economist, 2018).

Overuse can lead to abuse. Any published admissions algorithm that relies heavily one or a small number of factors is prone to manipulation and, in some cases, deliberate fraud. Beyond the hiring of private tutors discussed above, there are numerous cases of submission of fraudulent SAT and ACT scores created by paid imposters taking the tests for someone else, or income-motivated teachers correcting the penciled answers of their students (Paris, 2020). As we write this, some teachers found guilty of test score changing are in jail, and there are lawsuits pending with regard to imposters. College students found guilty of submitting fraudulent college applications are being expelled. 
Donald Campbell proposed an axiom in 1979 that is now known as "Campbell's Law":

"The more any quantitative social indicator is used for social decision-making, the more subject it will be to corruption pressures and the more apt it will be to distort and corrupt the social processes it is intended to monitor." ... When test scores become the goal of the teaching process, they both lose their value as indicators of educational status and distort the educational process in undesirable ways" (Campbell, 1979; our emphasis).

The recent corruptions we have seen with regard to test score manipulations are exemplars of Campbell's Law in action. In college admissions, however, Campbell's Law is not limited to test scores. The applicant's personal statement is deemed very important, and affluent families may hire a "college application consultant" to assist with the entire effort. This can result in ghostwriting of the applicant's personal statement and other required statements. And it may entail exaggeration of aspects of the applicant's academic life, such as involvement and accomplishment in extracurricular activities (Selingo, 2019). Corruption ingenuity knows few bounds; we recently heard about South Korean academics naming their young children as coauthors of their academic papers to give the children impressive resumes when they apply to college (Zastrow, 2019). In the United States, "Operation Varsity Blues" (Pascus, 2019), involving bribes often in the hundreds of thousands of dollars, now stands as a new exemplar of corruption. Many have come to take a cynical view the college application process as a "game" rigged for the well-to-do (Craig, 2019; Korn, 2019).

Colleges and universities themselves are not always innocent in the college admissions game. They can "buy" names of talented high school seniors and send them correspondence urging them to apply. While this sounds inviting, the game here is for the college or university to obtain many more applications than usual while keeping the number of students admitted constant, thereby making the college look "more exclusive" than it really is (Belkin, 2019). Exclusivity implies prestige.

\subsection{Let's Get Serious with College Admissions}

The rich-poor test performance gap has been studied widely. For example, Reeves and Halikias report a stubborn black-white achievement gap (about 0.92 standard deviations) in SAT scores that remaining essentially unchanged for 20 years, from 1996 to 2015 (Reeves \& Halikias, 2017). Our proposed ePortfolio process should reduce biases associated with standardized tests: gender, race, community wealth, and family wealth. We believe portfolios-along with, of course, learning opportunities that will in turn create content for them-offer an alternative and academically fair route to college for disadvantaged students, giving them a chance to demonstrate their abilities to achieve excellence via passionately created artifacts in their portfolios. This is not necessarily an "easier path" for any student, advantaged or disadvantaged. Portfolio creation will re- 
quire lots of work. But that work will be largely without all the built-in biases of standardized, multiple-choice tests.

Standardized tests have a "flaw of averages." A single number, by nature, is not capable of capturing individuals' targeted excellence. A student with an " $A$ " in one subject and a "C" in another would average a "B" overall. Suppose a second student has two B's. A summary average of grades fails to distinguish between these two students and would rank them equally. However, if the A's of the first student are related to her passion, interests, and true accomplishments, she might be a better candidate for many programs. In addition to averages, we are interested in variances and entire distributions. Portfolios give each student the opportunity to provide artifacts from the "right-hand tail" of his or her personal distribution.

As we have already discussed, given the growing awareness of the problems of standardized tests, many colleges-including Harvard, Stanford, Yale, Duke, Brown, University of Chicago, and California Institute of Technology—have recently announced being Test-Flexible, Test-Optional, or Test-Blind (Jaschik, 2018; Anderson, 2020). Test-Optional schools leave the decision up to admissions candidates whether to include test scores. Test-Flexible schools still require tests scores but are flexible to wave them in special cases. Test-Blind schools (such as Hampshire College) do not permit students to submit test scores. According to the 2018 data, among the US News top 50 liberal art colleges, 32 schools are test-required, 12 are Test-Optional, six are Test-Flexible, and none are Test-Blind. Even for test-required schools, however, not all portions of the SAT are required.

Adults using their resumes when applying for jobs proudly point to the multi-faceted nature of previous accomplishments, rarely if ever citing a numerical score on a standardized test or a letter grade from college. Employers, in evaluating applicants, may have focused screening criteria, such as requiring a minimum number of years of experience. But such criteria are easy to defend and difficult to manipulate-and manipulation, if found, disqualifies applicants from further consideration. In short, Campbell's Law types of manipulation are much more difficult in the professional world. For most professional-level positions, there is no formula for the successful applicant, no algorithm to plug into. And employers often celebrate an applicant's exceptional past performance in one or a small number of activities, in contrast to evaluating on overall averages.

Our key question, therefore, is this: Why don't we evaluate student applicants to higher education as we evaluate adults applying for jobs-in effect, treating college-seeking 18-year olds as adults? After all, 18-year-olds in the United States can vote, join the military, consent to sexual relationships with someone 18 years or older, donate blood and become an organ donor, work full time, play the lottery, purchase and use tobacco products, establish bank accounts, apply for a loan, get married, file a lawsuit, create a will, purchase a vehicle, purchase a house, adopt a child, ... 


\subsection{College Admission after the Pandemic}

The first draft of this paper was completed in December 2019, just before the COVID-19 pandemic. In these unprecedented times, concerns have been raised about college admission both from college and family sides. High school students and their families are concerned about the impact of COVID-19 on their admission processes, and universities are concerned about student health, remote-learning effectiveness, and school enrollments. An immediate impact of the pandemic on the college admission deals with the uncertainties related to the standardized tests. As of this writing, the testing companies are yet to determine the time and location of their testing during Summer and Fall 2020 (LaScala, 2020). The delay and uncertainty of the standardized testing will impact student decisions on selecting their colleges, especially those who could otherwise make early decisions.

After, or during, the pandemic, colleges and universities will have a new set of admissions issues that take into account many challenges and obstacles that high school students have faced in these difficult times. Through an initiative at Harvard's Graduate School of Education, more than 200 admission leaders endorsed a significant shift in college admissions after the pandemic. This collective statement highlights schools' commitment in student self-care, balance, meaningful learning, and care for others as a new set of goals within their missions (MCCP, 2020). In this initiative, more weights will be given to students' challenges and achievements during the pandemic. With more value given to student extracurricular activities, ePortfolio preparation helps students effectively to share their experiences about study-from-home, learning experiences during the pandemic, self-care experiences, and possibly care for others.

In the new era after the pandemic, colleges and universities realize that admitting the right students to the right programs is key. Student motivations and interests play important roles in remote learning that can be illustrated using ePortfolios.

Roadmap: The remainder of this paper presents the need for a new ePortfolio system replacing or at least augmenting the current standardized tests in the college admissions process. In Section 2, we describe the ePortfolio and explain how the process of creating an ePortfolio can extend and deepen a student's critical thinking skills and provide opportunities for personal reflection on her/his learning goals accomplishments. In Section 3, we review the academic literature, including a discussion of recent reported advances in ePortfolio development. Section 4 delves more deeply into aspects of an ePortfolio, including a description of how a highly-vetted and secured ePortfolio can be created. In this section, we also provide an ePortfolio example created by a current Massachusetts high school student toward his college admission. Implementing an ePortfolio into the overall college admissions comes with challenges including ePortfolio assessment. In Section 5, we offer a procedure that can be implemented in college admissions offices in order to improve and systemize ePortfolio assess- 
ment. In Section 6 we discuss in more detail student reflective learning. In Section 7 , we offer concluding remarks and propose directions for required system change.

\section{Introducing the ePortfolio}

We propose the widespread use of student portfolios, or ePortfolios (as they will be implemented on computers) (Larson, 2019). For a high school student, a portfolio serves a role analogous to a resume for a practicing professional. But it is even more. An ePortfolio will be a structured, searchable, online multimedia collection of a student's accomplishments, artifacts, and performances-those outside of routine class assignments and exams-that demonstrate creativity, perseverance, deep learning, and collaborative skills. We argue that a student's ePortfolio should become an integral and required part of the college admission process.

An ePortfolio will most often contain text, images, and video, ordered by date and topic. For instance, an accomplished athlete can include video clips of her athletic prowess. A student who volunteered with a local charity can provide video testimonials to his unselfish giving and effectiveness to the community. A budding scientist can show images and videos of her prize-winning science fair project. An emerging engineer can show drawings of his best maker designs. And, if high school curricula adopt project-based learning, there is potentially much more.

\subsection{Project-Based Learning}

ePortfolios will reach their full potential only when Project-Based Learning (PBL) becomes a standard, recurring, and important component of high school education. What is PBL? While there is no concise consensus answer, PBL has the following attributes (Larson \& Murray, 2019; Grossman, 2019):

1) PBL involves students in solving, or at least making progress on, real-world, phenomenon-based problems in a process from which they apply the associated science, math, and/or engineering.

2) The teacher's statement of the problem is almost always more expansive than a typical homework problem, lacking sharp boundaries. Since there are no right or wrong answers, this situation may create great stress-especially among students accustomed to finding the "correct" answers, knowing when they're "done," and typically achieving high grades through that process.

3) Students work in small teams, building collaborative skills as they seek to think as scientists or engineers when addressing their assigned PBL problem.

4) A PBL assignment requires students to work both in and outside of school, for periods lasting between a week and an entire school year. Typical PBL assignments last several weeks.

5) The process is one of student research and discovery, applying fundamental knowledge learned in class to frame, formulate, and develop insights for the 
stated problem, which is hoped will lead to recommendations for actions to address the stated problem.

6) There are opportunities for students to "Go Deep," beyond grade-level textbook content, thereby creating the opportunity to create valuable artifacts for ePortfolios: student-created reports, presentations, videos, testimonials, and so on.

7) The "final product" is often a public oral presentation, accompanied by a written report. Community stakeholders in the chosen problem area can be invited to attend and offer feedback, implying additional possible artifacts for the ePortfolio.

Gaining traction, seemingly every week, is the idea of assessing students on the "growth mindset" accomplishments and deep learning found in their ePortfolios rather than on standardized test scores (Education Dive, 2019).

\subsection{Portfolios: Not So New!}

The student portfolio is not a new idea. They have been utilized for student evaluation for many years in architecture and the fine and performing arts. Like these disciplines, STEM fields also require creativity, imagination, passion, teamwork, and demonstrated excellence. STEM students should be evaluated along these dimensions, in addition to the usual letter grades, test scores, and listed extracurricular activities. While the use of STEM portfolios in American high schools is growing, the practice is still not common. To bring it to scale, major stakeholders-parents and their children, high school teachers and administrators, and college admissions officers-must see its benefits. Some standardization, with concomitant privacy/security measures, is required. In addition to stakeholder consensus, one needs certain educational system changes, especially for teachers: teacher Professional Development in PBL and in mentoring students in portfolio creation (Darling-Hammond et al., 2017).

\section{Literature Review and Current Practice}

As mentioned above, admitting students based on their portfolios has been practiced in architecture and the fine and performing arts for many years. In these fields, all candidates are required to submit a portfolio to show their creativity, understanding of principles, and particularly relevant skills. Examples of specific requirements run the gamut from Syracuse University's requirement that candidate for its undergraduate architecture program submit at least 20 work samples, 25 for Cornell University (Bergman 2017), and NYU's art school specifying that applicants must demonstrate mastery with either a scale model with figures, a scale ground plan for that same model, or architectural structure. Stanford applicants must show they are a good fit for the program by providing tangible artifacts and relating them to the college's mission. In most schools, after reviewing the applications, selected students are invited for on-campus interviews and face-to-face auditions related to their portfolios. 
High school and college students not in architecture and the fine and performing arts sometimes have difficulties with creating portfolios and understanding their value, and adopting the portfolio option comes with challenges. Black et al. (1994) represented and explored the tension and ambiguity of portfolio assessment and offered a range of approaches to improve student understanding of the portfolio and its applications. McDonald (2011) discusses that a portfolio creates a subjective form of assessment, a major transformation for teachers and students accustomed to using grading keys and answer sheets. To reduce subjectivity, portfolio implementation becomes easier with detailed rubrics to support uniform grading. (Yancey, 2009) categorized portfolios into evidence-based documents and provided a detailed rubric to assess portfolios that was later adopted at the Standards for Educational and Psychological Testing (AERA, APA, \& NCME, 2014). According to this documentation, an effective portfolio assessment helps students learn about their strengths and weaknesses and suggests a pathway for career selection.

Grading fairness is an oft-raised concern with portfolios. In an empirical study, (Kelly-Riley, Elliot, \& Rudniy, 2016) addressed grading biases with respect to race and student background and reported a lack of fair grading by race, even when there are detailed rubrics. In a survey analysis, (Marshall, Duffy, Powell, \& Bartlett, 2017) asked, "How confident are faculty members about their own portfolio grading?” (Heinrich \& Rivera, 2017) provided an assessment method for reflective artifacts specifically using self-recorded videos. Finally, the very idea of "letter grading" in the traditional sense may be oxymoronic with portfolios; a portfolio assessment may require, at a minimum, a paragraph written by the assessor-which is better than letter grading.

Much of the literature on ePortfolios focuses on higher education. In a survey analysis of college students studying pharmacy, (Murphy, Airey, Bisso, \& Slack, 2011) realized that the first-year students did not know how to build a portfolio and demanded more samples, but the third- and fourth-year (college) students required more feedback and personal time with their advisors. The authors concluded that the portfolio development process requires good instruction and supervision. Portfolio acceptance, however, is related to social factors. (Ahmed \& Ward, 2016) showed a strong relationship, at a UK university, between students' acceptance and implementation of ePortfolios and their personal, social, and economic wellbeing. Since college students have difficulties with portfolios, we should not underestimate the many possible hurdles with high school students.

The student portfolio plays crucial roles in other countries' higher education systems. A comprehensive study by (EuroPortfolio, 2015) argues that although Europe was slow in making the switch from the teacher-centered to the student-centered method of learning, the current higher education system-equipped with ePortfolios-is becoming standard and sustainable. In colleges and universities, the ePortfolio adaptation enhances students' reflective and deep learning. According to this report, leading countries in using ePortfolio in 
higher education are Austria, Denmark, Germany, Poland, and the United Kingdom. (Kim \& Shon, 2010) investigated the standardization of ePortfolios in the South Korean education system, explaining that country's learner information model and highlighting the now-popular ePortfolio.

Our concern, again, is a more difficult one: extending the use of ePortfolios into secondary education, then bridging their use to the college admissions process.

One leader in this effort is MIT, the first author's home institution, where over 10 percent of current applicants to the freshman class now submit what the school calls "Maker Portfolios". The Maker Portfolio "is an opportunity for students to showcase their projects that require creative insight, technical skill, and a hands-on approach to learning by doing. Members of the MIT Engineering Advisory Board review all Maker portfolios" (MIT Admissions, 2019).

\section{Creating a High School ePortfolio}

The program closest to what we propose is operated by the Coalition for College Access (http://www.coalitionforcollegeaccess.org), a group of more than 150 colleges, that offers a free set of online planning tools for students applying to colleges. The group's initiative aims at standardizing college applications across schools and include an option to submit artifacts in a secure ePortfolio platform it calls the student's private "Locker." The aim is to reduce the time student's must spend on the application process, and in turn the accompanying stress. In 2018, 345,000 college applications were submitted through the Coalition (Jaschik, 2019). We do not know the fraction of these that had additional materials submitted in accompanying student private Lockers.

Like the Coalition for College, we support the implementation of the ePortfolio in the college admission process. The college could decide the weight given to an ePortfolio. Or, intriguingly, the applying students could suggest the weight that should be given to their portfolios. Our preference is that portfolios be examined for all applicants that meet the minimum school requirements for acceptance (e.g., GPA, reference letters, etc.) and then be weighted at least equally with SAT or ACT scores.

In our model, creating an ePortfolio begins in the freshman year of high school. Towards the end of each year, students add to their ePortfolios using new PBL artifacts, leadership tasks, science fair projects, extracurricular activities (with official school confirmations of participation), and possible certifications. Superlative classwork can also be included, as can special achievements in assignments or examinations. Leadership activities, such as serving as a class or student council member or office, can be highlighted. Students who engage in community service can illustrate those activities with flyers, photos, and other material. Each year the student also writes a candid short narrative, reflecting on her learning during the year-including disappointments and positive surprises-and on aspirations for the coming year. This is a major step away from the 
rote learning of standardized tests to written reflection on one's own-hopefully deeper-learning. From rote to wrote! As stated by Hodges, "Standardized summative assessments gauge knowledge, whereas portfolios aim to measure what matters: the progress and process of learning" (Hodges, 2019).

Portfolios are created using electronic software, and like the Coalition for College's student Lockers, are stored on a secure remote server. The material belongs to students and neither schools nor the remote server provider can access ePortfolio information without the student's written permission. To ensure authenticity, all content uploaded to the secure server must be e-certified by an appropriately trained teacher who is familiar with that student's learning trajectory, accomplishments, and goals. To ensure that no subsequent changes are made, we would insist on Read-Only format after submission. The Read-Only constraint would apply to the student as well as all others; this assures that contents cannot be altered at any time by anyone after they are uploaded to the ePortfolio. We envisage four years of such uploads, one for each year of high school. These four-year-long security features, including the digital sign-offs of knowledgeable teachers, make it very difficult if not impossible for any student, advantaged or disadvantaged, to corrupt the contents of an ePortfolio. The ePortfolio presents a secure and level playing field for all students.

At the end of high school, students own a comprehensive ePortfolio to which permitted access can be customized for different purposes, including applying for college admission or getting a job. For college admission, students submit their ePortfolios or subsets thereof, including review reports of the high school staff, along with other material typically required. For jobs, students can use their ePortfolios in an interactive resume format that lists skills and experiences and includes artifacts of superlative work.

\section{1. ePortfolio Features}

In our model, a self-created ePortfolio has the following features.

- Mixed Mode Annual Assessments: Each year of high school, rather than calculating GPA's based on standard metrics such as exams and homework assignments, a combination of both the standardized metrics and ePortfolios may be used. The high school's teachers or staff will determine relative importance weights. Each year, a comprehensive teacher-written year-end evaluation that includes the student's improvement and her goal-oriented direction will be added to the ePortfolio.

- Reflective and goal-oriented: With ePortfolios, the beginnings of a goal-oriented career pathway can be observed in the sequence of student-selected activities and projects. Ideally, this time-marked set of activities and accomplishments will reflect students' evolving learning objectives, improved learning outcomes, and growing maturity as learners. Students learn to be goal-oriented by observing and reflecting on their experiences.

- Customizable and user-friendly: The ePortfolio would be created over four 
years of high school, with great flexibility on the part of the student in determining its contents and formatting. A portfolio management system would enable students to prepare customizable documentation and rearrange a portfolio for different purposes. Overall, an ePortfolio in our conceptual model is different than simply collecting multiple documents in a folder. Rather, it is a user-friendly way to retrieve and present information, almost in the form of a narrative story.

- Reliable, trustworthy, read-only documentation: Information reliability is crucial for any admission or hiring process. At present, students prepare college applications only a few months prior to the deadlines-a stressful period during which some recruiting companies go beyond their responsibilities and, unethically, frame a resume or an application in such a way that it no longer represents the candidate's own work. As mentioned above, our model makes it almost impossible to corrupt a four-year data stream about student activities reported in an ePortfolio. Most items are projects or activities that are vetted by high school instructors or supported by acknowledged letters and licenses. All components of an ePortfolio are required to be reviewed and approved by authorized and certified high-school instructors or officials. Approved sections of an ePortfolio remain Read-Only and require the approval of the school's official for updates.

Having access to a secure electronic platform to create and maintain portfolios assures the project feasibility. Ideally, every school supporting the ePortfolio program would license an ePortfolio management system that stores data remotely on a secure server. Existing commercial systems let students gather and organize work in one place, update previous projects, and finally decide which work (or sequence of works) to include for different purposes. Providing licensed software to high schools to create ePortfolios creates opportunities for all students, including those from disadvantaged backgrounds. Any student seeking technical help with the system can obtain that help from the company provider with no additional cost.

Several portfolio software companies serve universities with systems that fit our model, including WIX.com, Krop.com, ClassDojo.com, and portfoliopen.com. The award-winning Digication.com ePortfolio system may be the best fit with our model. It links together all students and teachers and allows students to select projects based on an institution-defined mission and according to teacher instructions. Data-driven reporting supports assessment of students and update the institution's mission and policy. There are extensive settings to ensure privacy.

\section{2. ePortfolio Content Illustration}

To illustrate just one ePortfolio content area, and especially to show just how it could be used to present student work and experiences through an ePortfolio, we offer the following case of a young Massachusetts student. It highlights several 
important aspects of our argument in this paper: that high school students-and disadvantaged students in particular, because of biases-need a better way than standardized test grades to present their capabilities to college admissions offices; that these capabilities can be uncovered in project-based learning; and that ePortfolios are an ideal way to present these capabilities.

In 2019, Jhanny Jimenez was a 15 -year-old sophomore at Notre Dame Cristo Rey High School (NDCR) in Lawrence, Massachusetts, a small, private Catholic college preparatory high school at which more than 90 percent of the students are Latino/Hispanic (mostly Dominican and with Spanish as their first language) and the entire student body is eligible for federal aid for lunch. Most students are the first in their families to attend college. NDCR students, selected through a very thorough review of economic need and an interview process, wear uniforms to school, are taught how to interact maturely with teachers and other adults, and learn in a supportive school environment, founded by the sisters of Notre Dame de Namur, that has almost zero disruptions. It's a school culture in which everyone wants to learn and is focused on getting to and through college.

Perhaps the most novel feature of the NDCR program is that students attend school only four days a week and, on the fifth day, are brought to paid apprenticeship jobs at Eastern Massachusetts high-tech and other firms, hospitals, and government agencies. Each student has a senior mentor/supervisor at his or her job. The apprenticeships provide numerous opportunities for students to undertake real and often deep and complex work that builds on knowledge they acquire in the classroom. They are challenging, not make-work jobs, and the challenges grow as students move through their four years of high school. Over that period, each student spends nearly the equivalent of an entire year in a job-focused professional mentorship. Student salaries go directly to the school and pay the great majority of students' tuition (the rest of which comes from charitable donations).

On November 12, 2019, Jhanny Jimenez presented his latest work at MITRE Corporation in Bedford, Massachusetts (Figure 1). His paper, "PALMA ${ }^{\mathrm{Tm}}$ as a Visualization Tool", was coauthored with his senior mentor Dr. Les Servi of MITRE. It exemplifies the kind of content that can be a valuable addition to an ePortfolio used in the college admission process. In fact, each job project in these apprenticeships provides artifacts that could be part of an ePortfolio.

The apprenticeships can be viewed as project-based learning, supervised not by harried in-class teachers, but by full-time professionals at work. These apprenticeships open the eyes of students to see substantial professional roles for themselves in the future-roles that will require additional education after high school. This is a supporting feedback loop, a virtuous cycle in which success in obtaining knowledge in school leads to more skills and success at the internship, and internship success leads to more motivation for in-school learning.

At present, NDCR does not formally use the types of ePortfolios we are discussing. But the school does ask student apprenticeship mentors for detailed letters of recommendation. Along with accompanying artifacts such as a copy of 


\section{PALMA ${ }^{\mathrm{TM}}$ as a}

Visualization Tool

Jhanny Jimenez-Feliz

T841 intern and a sophomore at Notre Dame

Cristo Rey High School

Mentored by Dr. Les Servi (T841)
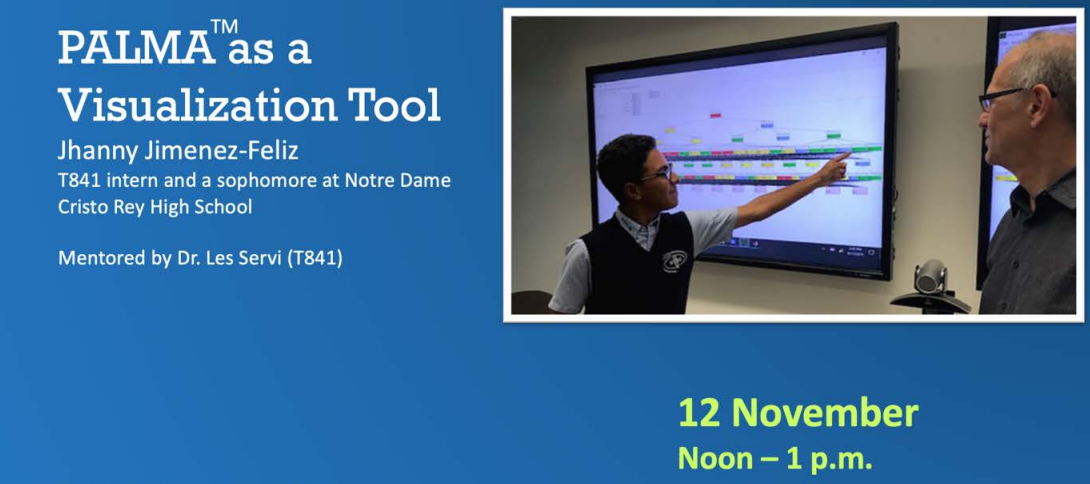

FastJump: DA CoP

12 November

Noon -1 p.m.

2M148, 5J124 / Skype: 61059673

Figure 1. Opening PowerPoint of the Jhanny Jimenez presentation. (PowerPoint Approved for public release. Distribution unlimited 18-03899).

Jhanny's paper with PowerPoints, these letters go a long way towards helping students in the college application process. Imagine how much more compelling a case for college acceptance Jhanny could make with an ePortfolio that included his presentation at MITRE.

One last note: In each of the past 12 years, 100\% of NDCR graduates have been accepted to four-year colleges and universities. The 36 other high schools in the Cristo Rey national network also enjoy huge (but not always 100\%) success (private communication; see also Cristo Rey Network, 2019; Whitman, 2009).

\section{Portfolio Assessment}

Assessing the capabilities of an applicant via an ePortfolio is more involved than reading scores from standardized tests. It takes more time of the human evaluator and greater concentration, resulting in admittedly subjective judgments. But subjectivity is not a weakness. Was there a formula for assessing the contributions of Einstein, Shakespeare, or Marie Curie? Even today's traditional test-oriented assessment processes are, in the end, highly subjective. In a typical year, MIT refuses admission to 200 or so applicants with perfect SAT scores and 300 with perfect ACT scores. Decisions are made on subjective assessments of the other components of these students' admissions applications. Here, subjectivity is not at odds with objectivity.

Portfolios add lots of content to traditional applications. The human reader may become overwhelmed. Thankfully, ePortfolio software systems typically have standardized formats and structure, and all applicants should use them. This makes working with ePortfolios easier for college admissions offices. Assessment is also easier if high school teachers certifying portfolios use a common language. Here again, we are in luck. ePortfolio software packages provide standard or user-defined keywords to characterize students and their work. Teachers 
assign and update the keywords throughout the four years of high school; examples include "problem solving," "comprehensive learner," "real-world project involvement," "creative idea," and "teamwork." Such keywords are stored in a data dictionary.

We can now leverage the common language structure described above to depict succinctly a student's learning path over four years of high school, his/her project-based accomplishments, extracurricular exceptionalism, admitted failures, evolving academic passions, visions for the future, and so on. To operationalize the idea, we define a student's knowledge mapping as the time-sequenced distillate of keywords and comments high school teachers provide as input for a student's portfolio. Teachers may add or remove keywords based on student performance (for example, removing "lack of writing skill" after that is resolved) and add comments or highlights if appropriate. A knowledge map is then generated from the history of these keywords: the portfolio management software provides summary reports, recommends new keywords, merges multiple keywords into one, and creates a map of the student's learning pathway during high school. The map thus shows a student's improvement in knowledge and how that student's interests evolved.

The information in a knowledge map aids in the assessment of an ePortfolio. The left side of Figure 2 shows the knowledge mapping process; the right side situates the knowledge map as part of the college admissions process. An ePortfolio's common formatting, data dictionary, and knowledge map can greatly assist the admissions' office work. But, even with these concentrated partial depictions of a student, we suspect that virtually all strongly competitive applications will require that college admissions officers read many details beyond keywords and the knowledge map.

\section{The Student's Reflections on Learning}

The ePortfolio creation process requires students to self-reflect on their evolving competencies, interests, passions, and accomplishments. Self-reflection is an integral part of true learning. In creating a portfolio, students are intensely involved with active selections of their own projects and their evaluation. Creating portfolios is a Reflection-In-Action process (see Schön, 1983). By reflecting on their own experiences, students can learn about their own learning pathways and continue to build on it during college. Figure 3 shows the interaction between project selection and outcome through reflective learning.

In an experimental study, (Lewis, 2015) studied reflective-learning and named three skill categories that can be enhanced by creating a portfolio: metacognitive skills through portfolio creation; attitudinal awareness through portfolio journals; and expressive learning through visual narrative. Creating an ePortfolio with reflective learning during high school can enhance these skills.

A complete ePortfolio contains student reflective writing from throughout the four years of high school. In successful reflective learning, students generate 


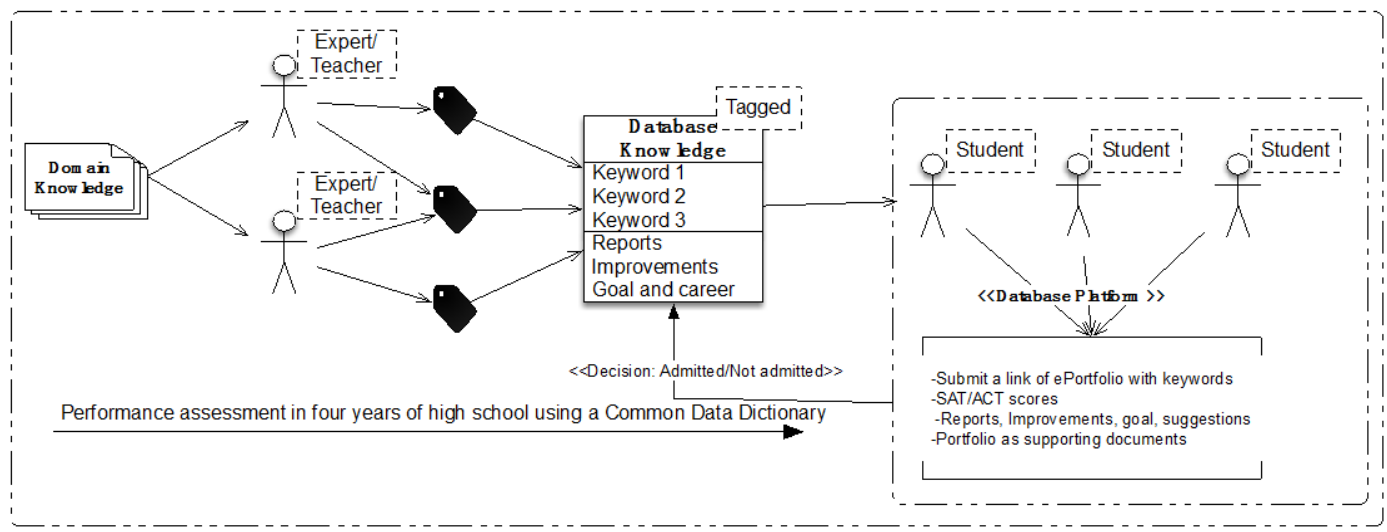

Figure 2. Implementing an ePortfolio into the overall college admissions process.

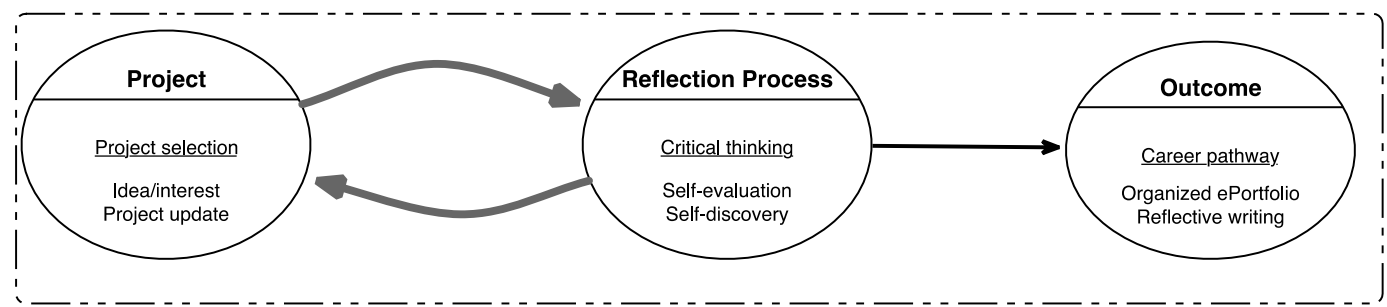

Figure 3. Reflective learning through project development.

time-sequenced "messages" that represent their evolving learning passions and academic choices during each of their four years of high school. The student provides his/her interpretations of the relationships between experiences, and critically examines each project. A student's emerging professional identity grows before our eyes!

\section{Reflections and Conclusions}

We have proposed introducing four-year ePortfolios for high school students, with teacher-certified content featuring the best of the student's activities and accomplishments in each of her four high-school years. We see this as a way to overcome most of the biases in the college admissions process discussed at the beginning of this paper. But it can be much more. Coupled with the concomitant changes involving regular use of Project-Based Learning, reduced emphasis on standardized test scores, and required new teacher training and support, we have a substantial educational structural change that will produce a new type of student: an active learner taking ownership of her/his growing STEM knowledge, proud of her/his accomplishments, willing to take risks, going deep on projects, and thinking about the future.

This is in sharp contrast to the tunnel vision of those who laser-beam their efforts toward time-constrained multiple-choice standardized tests. One cannot help but wonder whether Albert Einstein would have thought about general relativity had he been forced to spend hundreds of hours studying for standardized tests. Such tests lead to standardized thinking. Would college dropout Steve Jobs 
have created the elegant Macintosh computer had he not taken that calligraphy course (Rosoff, 2016)? Calligraphy is not on any STEM standardized test.

Our education system needs to encourage diversity of thought and priorities among students, letting them follow their passions. We need to produce more deep-thinking, out-of-the-box STEM innovators, not standardized-text takers.

Widespread, effective deployment of ePortfolios will require significant structural changes in the U.S. educational system. The following three are most important.

- College admissions offices must reduce the importance weights of the SAT and ACT tests by at least $50 \%$ and reallocate that to the assessment of ePortfolios.

This would obviously be a major change in the college admissions process. One recent report suggests that college admissions offices, operating in teams of two, typically spend only 8-to-10 minutes reviewing an applicant, after which the decision is made: admit, deny, waitlist. Only a small fraction (typically $10 \%$ to $15 \%$ ) is given a second look (Korn, 2018). Even with refined computer-based categorization and assessment tools like those described in Section 5, admissions office evaluators will have to devote additional time to ePortfolios. A deeply nuanced assessment of a student who passes initial screening may require an additional 30 to 60 minutes of admissions office time-a small price to pay for a decision that will affect the remaining decades of that student's life.

The other two important changes concern high schools.

- High schools must make the creation of ePortfolios standard operating procedure for all students beginning in their freshman year.

- To create opportunities for students to add meaningful content to their ePortfolios, high schools must include Project-Based Learning as a substantial component of their curricula.

The latter two will require significant new training and professional development for teachers, as ePortfolios and project-based learning will be new in most school districts. The needed reorientation will likely take time away from state-mandated curricula that emphasize standardized tests. That tension must be resolved; a shift in the college admissions process along the lines we recommend above will put pressure on schools to do so. Students who emerge from such a new active and exploratory learning system will no longer be blinders-wearing test takers, as they will have developed deep interests in various aspects of science, engineering, and mathematics, with superlative ePortfolio-demonstrated work.

The Notre Dame Cristo Rey High School and its 37-school Cristo Rey network represent an existence proof that structural change can lead to education success, even for the most underprivileged students. There are numerous similar "quasi-experiments" throughout the United States, many of which have also demonstrated exciting superlative results. We should learn from these and over time-fine-tune our proposed system structural changes. 
The journey to national scaling of these ideas will likely be a long one. But the importance of that journey cannot be overstated. Our students' future and our nation's future depend on it.

\section{Acknowledgements}

For his open discussions about MIT's admissions process, we thank Stuart Schmill, MIT Dean of Admissions and Student Financial Services. We also thank the following for supporting the work and ideas reported herein: Mr. Glenn Strehle and the Lounsbery Foundation, Mr. Linc Miller and The Open Education Resources Foundation Inc. of Florida, NTT Com Asia Ltd., Trumptech (Hong Kong) Ltd. Limited, the Hong Kong Innovation and Technology Fund (ITS/212/16FP) under the HKUST-MIT Research Alliance Consortium. Findings and opinions expressed herein are those of the authors and do not necessarily represent those of the sponsors or of MIT.

\section{Conflicts of Interest}

The authors declare no conflicts of interest regarding the publication of this paper.

\section{References}

Ahmed, E., \& Ward, R. (2016). Analysis of Factors Influencing Acceptance of Personal, Academic and Professional Development e-Portfolios. Computers in Human Behavior, 63, 152-161. https://doi.org/10.1016/j.chb.2016.05.043

American Educational Research Association (AERA), American Psychological Association (APA), \& National Council on Measurement in Education (NCME) (2014). Standards for Educational and Psychological Testing. Washington DC: AERA.

Anderson N. (2020). Colleges Are Ditching Required Admission Tests over Covid-19. Will They Ever Go Back? Washington Post. https://www.washingtonpost.com/local/education/coronavirus-sat-act-admission/2020 106/15/18c406dc-acca-11ea-a9d9-a81c1a491c52_story.html

Baldiga, K. (2013). Gender Differences in Willingness to Guess. Management Science, 60, 434-448. https://doi.org/10.1287/mnsc.2013.1776

Belkin, D. (2019). For Sale: SAT-Takers' Names. Colleges Buy Student Data and Boost Exclusivity. Wall Street Journal. https://on.wsj.com/2oPNAkJ

Bergman, D. (2017). Which Colleges Require Portfolios? College Transitions, November 2017.

Black, L., Daiker, D., Sommers, S., \& Gail, S. (1994). New Directions in Portfolio Assessment: Reflective Practice, Critical Theory, and Large-Scale Scoring (p. 82). College of Arts \& Sciences Faculty Books.

Broussard, M. (2014). Why Poor Students Can't Win at Standardized Testing. The Atlantic.

https://www.theatlantic.com/education/archive/2014/07/why-poor-schools-cant-win-at -standardized-testing/374287

Campbell, D. T. (1979). Assessing the Impact of Planned Social Change. Evaluation and Program Planning, 2, 67-90. https://doi.org/10.1016/0149-7189(79)90048-X

Cristo Rey Network (2019). A Magnetic Movement. 
https://www.youtube.com/watch?v=qZCeDlG_WX0\&feature=youtu.be

Craig, R. (2019). The Mindblowing Hypocrisy of Elite College Admissions. Forbes. https://www.forbes.com/sites/ryancraig/2019/11/22/the-mindblowing-hypocrisy-of-elit e-college-admissions/\#47ac8a2a66ee

Darling-Hammond, L., Burns, D., Campbell, C., Lin Goodwin, A., Hammerness, K., Low, E., McIntyre, A., Sato, M., \& Zeichner, K. (2017). Empowered Educators: How High-Performing Systems Shape Teaching Quality around the World. San Francisco, CA: Jossey-Bass.

https://www.wiley.com/en-us/Empowered+Educators\%3A+How+High+Performing+S ystems+Shape+Teaching+Quality+Around+the+World-p-9781119369608

DeGeurin (2019). 27 Great Schools That Don't Require SAT or ACT Scores. Insider. https://www.insider.com/27-great-schools-that-dont-require-sat-or-act-scores-2019-7

The Economist (2018). Gaokao Gruel. The World's Most Important Exam Is Flawed. https://www.economist.com/leaders/2018/06/30/the-worlds-most-important-exam-is-f lawed

Education Dive (2019). Assessment Is Evolving - But Is Change Coming Fast Enough? https://www.educationdive.com/news/assessment-is-evolving-but-is-change-coming-fa st-enough/567861

EUROPORTFOLIO (2015). Thematic Report on the Use of ePortfolios in Higher Education. http://www.eportfolio.eu/sites/default/files/Thematic_Report_HE.pdf

FairTest (2007). Gender Bias in College Admissions Tests. https://www.fairtest.org/gender-bias-college-admissions-tests

Grossman, P. (2019). Preparing Educators for a Faster Future: The Promise and Challenge of Project-Based Learning. Harvard Education Publishing Group.

Harker, P. T. (2014). Commentary, Making Sense of Higher Education's Future: An Economics and Operations Perspective. Service Science, 6, 207-216. https://doi.org/10.1287/serv.2014.0079

Heinrich, B., \& Rivera, J. (2017). A Method for Assessing Experimental Learning for Eportfolio. International Journal on Innovations in Online Education, 1, 1-7. https://doi.org/10.1615/IntJInnovOnlineEdu.v1.i1.110

Hess, A. (2019). Rich Students Get Better SAT Scores-Here's Why. CNBC. https://www.cnbc.com/2019/10/03/rich-students-get-better-sat-scores-heres-why.html

Hodges, B. (2019). Portfolios Boost Assessment Relevancy for Truly Transformative Learning. Education Dive.

https://www.educationdive.com/news/portfolios-boost-assessment-relevancy-for-trulytransformative-learning/548118

Jaschik, S. (2018). For Fate of SAT Writing Test, Watch California. Inside Higher Ed, July 2018.

Jaschik, S. (2019). Leaving the Coalition. Inside Higher Ed, May 2019.

Kelly-Riley, D., Elliot, N., \& Rudniy, A. (2016). An Empirical Framework for ePortfolio Assessment. International Journal of ePortfolio, 6, 95-116.

Kim, Y., \& Shon, J. G. (2010). Korean e-Portfolio Standardization. In The 2010 9th International Conference on Information Technology Based Higher Education and Training (pp. 163-167). Cappadocia: IEEE. https://doi.org/10.1109/ITHET.2010.5480048

Korn, M. (2018). Some Elite Colleges Review an Application in 8 Minutes (or Less). Wall Street Journal.

Korn, M. (2019). How to Fix College Admissions. Wall Street Journal. 
Larson, R. C. (2019). A Tipping Point in the High School-to-College System: Op-Ed. New Haven Register. http://bit.ly/2KCzBrb

Larson, R. C., \& Murray, E. (2019). MIT BLOSSOMS-High School OER STEM Lessons Leading to Deep Learning, for Students and Teachers. In R. S. Feldman (Ed.), Learning Science: Theory, Research, and Practice (pp. 261-301). New York: McGraw Hill Education.

LaScala, E. (2020). The Impact of COVID-19 on College Admissions. pleasantonweekly.com, April 30, 2020.

Lewis, L. (2015). A Critical Reflection on ePortfolio as a Teaching Tool. New Zealand Journal of Teachers' Work, 12, 115-130. https://doi.org/10.24135/teacherswork.v12i2.179

Making Caring Common Project (MCCP) (2020). Care Counts in Crisis: College Admissions Deans Respond to COVID-19. Cambridge, MA: Harvard Graduate School of Education. https://mcc.gse.harvard.edu

Marshall, M. J., Duffy, A. M., Powell, S., \& Bartlett, A. M. (2017). ePortfolio Assessment as Faculty Development: Gathering Reliable Data and Increasing Faculty Confidence. International Journal of ePortfolio, 7, 187-215.

Mattern, K. D., \& Patterson, B. F. (2009). Is Performance on the SAT Related to College Retention? College Board Research Report No. 2009-7.

McDonald, E. (2011). Student Portfolios as an Assessment Tool. Education World. https://www.educationworld.com/a_curr/columnists/mcdonald/mcdonald025.shtml

MIT Admissions (2019). Creative Portfolios. https://mitadmissions.org/apply/firstyear/portfolios-additional-material

Mulhere, K. (2017). This High School Senior Is Spending \$1,700 on College Applications. Is That Insane or Normal? Times Magazine, December 26th 2017.

Murphy, J. E., Airey, T. C., Bisso, A. M., \& Slack, M. K. (2011). Student Evaluations of the Portfolio Process. American Journal of Pharmaceutical Education, 75, 132. https://doi.org/10.5688/ajpe757132

Paris, B. (2020). The Next Testing Scandal. Inside Higher Education. https://www.insidehighered.com/admissions/views/2020/01/21/next-testing-scandal-co uld-come-any-number-directions-opinion

Pascus, B. (2019). Every Charge and Accusation Facing the 33 Parents in the College Admissions Scandal. CBS News.

https://www.cbsnews.com/news/college-admissions-scandal-list-operation-varsity-blue s-every-charge-plea-accusation-facing-parents-2019-05-16

Reeves, R. V., \& Halikias, D. (2017). Race Gaps in SAT Scores Highlight Inequality and Hinder Upward Mobility. Brookings Report, February 1, 2017.

Rosoff, M. (2016). The Only Reason the Mac Looks like It Does Is Because Steve Jobs Dropped in on a Course Taught by This Former Monk.

https://www.businessinsider.com/robert-palladino-calligraphy-class-inspired-steve-job s-2016-3

Sandler, R. (2020). University of California System Will Drop SAT, ACT Requirement for Admissions. Forbes.

https://www.forbes.com/sites/rachelsandler/2020/05/21/university-of-california-system -will-drop-sat-act-requirement-for-admission/\#1821a0dd1928

Schön, D. (1983). The Reflective Practitioner: How Professionals Think in Action. London: Temple Smith.

Selingo, J. (2019). There Is No Way to Prevent the Next Cheating Scandal, Admissions 
Officers Are in No Position to Evaluate the Truthfulness of the Applications They Review. The Atlantic.

Strachan, M. (2019). Ban the SAT and ACT. Vice. https://www.vice.com/en_us/article/qvgyqm/ban-the-sat-and-act

Watanabe, T. (2019). Drop the SAT and ACT as a Requirement for Admission, Top UC Officials Say. The Los Angeles Times.

https://www.latimes.com/california/story/2019-11-23/uc-officials-recommend-droppin g-sat-admission-requirement

Whitman, D. (2009). Sweating the Small Stuff, Inner-City Schools and the New Paternalism (esp. Chapter 5). Washington DC: Thomas B. Fordham Institute Press.

Yancey, K. B. (2009). Electronic Portfolios a Decade into the Twenty-first Century: What We Know, What We Need to Know. Peer Review, 11, 28-92.

Zastrow, M. (2019). More South Korean Academics Naming Kids as Co-Authors. Nature. https://www.nature.com/articles/d41586-019-03371-0 